\title{
The Differences in Cardiac Rehabilitation Outcomes by Age in Myocardial Infarction: A Preliminary Study
}

\author{
Hyun Ho Kong, MD ${ }^{1,2}$, Heui Je Bang, $\mathrm{MD}^{1,2}$, Jae Ung Ko, $\mathrm{MD}^{2}$, Goo Joo Lee, $\mathrm{MD}^{2}$
}

${ }^{1}$ Department of Rehabilitation Medicine, Chungbuk National University College of Medicine, Cheongju;

${ }^{2}$ Department of Rehabilitation Medicine, Chungbuk National University Hospital, Cheongju, Korea

\begin{abstract}
Objective To determine the age-related changes in cardiac rehabilitation (CR) outcomes, which includes hemodynamic and metabolic factors, in patients with myocardial infarction (MI).

Methods CR was administered for 8 weeks to 32 men (mean age, 54.0 \pm 8.8 years) who underwent percutaneous coronary intervention for acute MI between July 2012 and January 2016. The exercise tolerance tests were performed before and after the CR. The results were stratified based on a cut-off age of 55 years.

Results In the whole patient group, the hemodynamic variables such as the resting heart rate $\left(\mathrm{HR}_{\mathrm{res}}\right)$, systolic blood pressure $\left(\mathrm{SBP}_{\text {rest }}\right)$, submaximal HR $\left(\mathrm{HR}_{\text {submax }}\right)$, $\mathrm{SBP}\left(\mathrm{SBP}_{\text {submax }}\right)$, and rate pressure product $\left(\mathrm{RPP}_{\text {submax }}\right)$ significantly decreased and the maximal $\mathrm{HR}\left(\mathrm{HR}_{\max }\right)$ and $\mathrm{RPP}\left(\mathrm{RPP} \mathrm{max}_{\max }\right)$ significantly increased. All metabolic variables displayed significant improvement, to include maximal oxygen consumption $\left(\mathrm{VO}_{2 \max }\right)$ and ventilation $\left(\mathrm{V}_{\text {Emax }}\right)$, anaerobic threshold (AT), and the maximal oxygen pulse $\left(\mathrm{O}_{\text {2pulsemax }}\right)$. However, upon stratification by age, those who were younger than 55 years of age exhibited significant changes only in the $\mathrm{HR}_{\text {rest }}$ and $\mathrm{RPP}_{\text {submax }}$ and those aged 55 years old or greater displayed significant changes in all hemodynamic variables except diastolic BP. Both groups displayed significant increases in the $\mathrm{VO}_{2 \max }, \mathrm{VE}_{\max }$, and AT; the older group also exhibited a significant increase in $\mathrm{O}_{2 \text { pulsemax }}$. The magnitude of the changes in the hemodynamic and metabolic variables before and after CR, based on age, did not differ between the groups; although, it tended to be greater among the older participants of this study's sample.

Conclusion Because the older participants tended to show greater hemodynamic and metabolic changes due to CR, a more aggressive CR program must be administered to elderly patients with MI.
\end{abstract}

Keywords Myocardial infarction, Cardiac rehabilitation, Exercise test, Hemodynamics, Age

Received February 20, 2017; Accepted May 11, 2017

Corresponding author: Goo Joo Lee

Department of Rehabilitation Medicine, Chungbuk National University Hospital, 776 1(il)sunhwan-ro, Heungdeok-gu, Cheongju 28644, Korea. Tel: +82-43-269-6227, Fax: +82-43-269-6228, E-mail: gjlee1225@gmail.com

ORCID: Hyun Ho Kong (http://orcid.org/0000-0002-0558-3693); Heui Je Bang (http://orcid.org/0000-0001-5280-122X); Jae Ung Ko (http://orcid. org/0000-0001-9310-2476); Goo Joo Lee (http://orcid.org/0000-0002-8436-4463).

@ This is an open-access article distributed under the terms of the Creative Commons Attribution Non-Commercial License (http://creativecommons.org/ licenses/by-nc/4.0) which permits unrestricted noncommercial use, distribution, and reproduction in any medium, provided the original work is properly cited. Copyright $\odot 2017$ by Korean Academy of Rehabilitation Medicine 


\section{INTRODUCTION}

Cardiac rehabilitation (CR) is known to improve patients' exercise capacity and health-related quality of life, which reduce the risk factors and mortality rates associated with cardiac diseases [1]. From the hemodynamics perspective, CR increases the tolerance to physical events associated with daily living activities by decreasing the myocardial oxygen consumption at submaximal workload [2]; in terms of metabolism, it is known to improve endurance by increasing the maximal oxygen consumption $\left(\mathrm{VO}_{2 \max }\right)$ and anaerobic threshold (AT) [3].

Despite these advantages, the average participation rate in CR is only $30 \%$ in the United States [4]. The participation rate in CR decreases particularly with age, which could be attributed to the accompanying comorbidities that interrupt participation in CR in the elderly and the biases of physicians who believe that CR would be less effective in the elderly population [5].

A study demonstrated that aerobic exercise significantly improved exercise capacity regardless of age [6]. Another study showed that CR resulted in significant improvement in exercise capacity across all ages; although the magnitude of improvement was small among those who were over 75 years old [7].

However, these studies compared changes only in quality of life indices and overall exercise capacity such as $\mathrm{VO}_{2 \max }$ and metabolic equivalent (MET) after CR [6,7]. Moreover, most studies on detailed hemodynamic and metabolic changes included only healthy adults without any underlying diseases $[8,9]$. Studies that included patients with coronary artery disease were limited by a high proportion of the elderly patients failing to achieve their true maximal cardiopulmonary limitation, which makes it difficult to accurately compare CR outcomes based on age [10].

Therefore, this study implemented a phase 2 CR therapy for patients who underwent percutaneous coronary intervention (PCI) to examine the age-related differences in CR outcomes in terms of hemodynamic and metabolic variables.

\section{MATERIALS AND METHODS}

\section{Patients}

From July 2012 to January 2016, a total of 597 patients who underwent PCI with acute myocardial infarction (AMI) in Chungbuk National University Hospital were referred to the outpatient phase 2 cardiac rehabilitation program. Among them, 103 patients (90 men and 13 women) who did not have a contraindication to exercise testing based on the American Heart Association's (AHA) guidelines [11], agreed to the CR program, and underwent an initial exercise tolerance test (ETT) as the first step. Among them, 39 patients (32 men and 7 women) underwent supervised exercise CR at the hospital for more than 7 weeks during the rehabilitation period of 8 weeks and received a follow-up ETT. The female patients were excluded from this study. A retrospective chart review was conducted to analyze the hemodynamic and metabolic changes according to age after CR in the 32 male patients. They were divided into two groups (16 each) based on a cut-off age of 55 years. The chosen cutoff age was appropriate since hemodynamic responses with exercise differ with age, such as decreased cardiac output and increased pulmonary artery pressure among those older than 55 years $[12,13]$.

With respect to the risk factors of AMI, a self-report questionnaire was administered to collect information on diabetes mellitus, hypertension, and smoking status among those older than 55 years old. Anthropometric measurements, such as the body mass index (BMI), were gathered at the time of disease onset.

Among the potential patients for $\mathrm{CR}$, those with contraindications for the ETT (such as untreated life-threatening cardiac arrhythmia or uncontrolled hypertension, symptomatic aortic stenosis, and acute heart failure), an acute systemic illness (e.g., musculoskeletal diseases, such as lower extremity amputation or arthralgia, and history of cerebrovascular disease) or respiratory diseases that can interfere with ETT [11] were excluded. The use of electronic medical records in the present study was approved by the appropriate Institutional Review Board of Chungbuk National University Hospital (IRB No. 201702-004).

\section{Study methods}

The patients underwent a symptom-limited graded ETT, based on the Modified Bruce Protocol, for an average of 39.4 days after the onset of AMI and subsequently participated in an 8-week CR program that focused on aerobic exercise. After completing the program, the pa- 
tients underwent another ETT. During testing, if any of the early termination criteria by AHA [11] were met, testing was terminated.

With respect to examination tools, the Quinton Q-Stress (Mortara Instrument, Milwaukee, WI, USA) was used for real-time electrocardiogram (ECG) monitoring and SunTech 247 BP device (SunTech Medical, Morrisville, NC, USA) was used for automatic blood pressure (BP) measurements. The Q-Stress TM55 (Mortara Instrument) was the type of treadmill used, and the TrueOne 2400 (Parvo Medics, Sandy, UT, USA) was used for respiratory gas analysis.

ECG monitoring and automatic BP measurements were used to measure resting heart rate $\left(\mathrm{HR}_{\text {rest }}\right)$ and $\mathrm{BP}\left(\mathrm{BP}_{\text {rest }}\right)$, submaximal (the third exercise stage) $\mathrm{HR}\left(\mathrm{HR}_{\text {submax }}\right)$ and $\mathrm{BP}\left(\mathrm{BP}_{\text {submax }}\right)$, and maximal $\mathrm{HR}\left(\mathrm{HR}_{\max }\right)$ and $\mathrm{BP}\left(\mathrm{BP}_{\max }\right)$. The respiratory gas analyzer was used to measure $\mathrm{VO}_{2 \max }$, maximal ventilation $\left(\mathrm{V}_{\mathrm{Emax}}\right)$, and AT. The maximal oxygen pulse $\left(\mathrm{O}_{2 \text { pulsemax }}\right)$ was obtained by dividing the $\mathrm{VO}_{2 \max }$ by the $\mathrm{HR}_{\text {max }}$.

The exercise intensity in the CR program was determined using the Karvonen formula [14] based on the $\mathrm{HR}_{\text {rest }}$ and $\mathrm{HR}_{\text {max }}$ measured during the initial ETT. Based on the risk classification for exercise training by the American Association of Cardiovascular and Pulmonary Rehabilitation guidelines [15], the exercise intensity in the first week of CR was set as $65 \%, 60 \%$, and $50 \%$ of the heart rate reserve for the low-, medium-, and high-risk groups, respectively. The exercise intensity was increased gradually, up to $85 \%$ by the 8 th week. The exercise intensity was adjusted so that the perceived exertion during exercise did not exceed 12-14 points according to the Borg Rating of Perceived Exertion Scale.

A single session of CR exercise lasted 50 minutes, which consisted of 10 minutes of warm-up, 30 minutes of prescribed exercise using a treadmill and cycle ergometer, and 10 minutes of cool-down. During exercise, telemetry was used to monitor the patient's ECG and HR, while BP was measured before, during, and after the exercise session. Patients visited the hospital once a week for supervised CR exercise and were instructed to perform home-based aerobic exercise for more than 5 days per week. The exercise intensity was reset each week using the target heart rate measured by telemetry during the supervised CR exercise.

\section{Statistical analysis}

The between-group differences were tested using the Mann-Whitney test for continuous variables (such as age, BMI, number of involved vessels, and ejection fraction measured prior to CR) and the Pearson chi-square or Fisher exact test was used for non-continuous variables (such as hypertension and current smoking status). A paired t-test was used for the statistical analysis of hemodynamic and metabolic changes before and after CR in all patients; while the Wilcoxon signed-rank test was used to determine the statistical significance of hemodynamic and metabolic changes before and after CR in the two groups based on age.

All statistical analyses were performed using the Statistical Package for the Social Sciences (SPSS) ver. 24.0 software (IBM, Armonk, NY, USA). The statistical significance level was set at a p-value of less than 0.05 .

\section{RESULTS}

\section{General characteristics of patients}

The mean patient age was $54.0 \pm 8.8$ years (range, 34-76 years); while the mean age in the young and old groups were $47.0 \pm 5.5$ and $61.0 \pm 5.3$ years, respectively. Other variables apart from age that can affect exercise capacity, such as diabetes mellitus, hypertension, BMI, current smoking, beta-blocker usage, and ejection fraction [16], were not significantly different between the two groups (Table 1).

\section{Hemodynamic and metabolic changes after CR in all patients}

After the 8-week CR therapy, among the hemodynamic variables, exercise duration $(+116.3 \mathrm{~s}), \mathrm{HR}_{\max }(+7.3$ beats/ $\min )$, and $\mathrm{RPP}_{\max }(+13.5)$ exhibited significant increases; whereas $\mathrm{HR}_{\text {rest }}(-5.3$ beats $/ \mathrm{min}), \mathrm{SBP}_{\text {rest }}(-2.9 \mathrm{mmHg})$, $\mathrm{HR}_{\text {submax }}(-5.8$ beats $/ \mathrm{min}), \mathrm{SBP}_{\text {submax }}(-9.1 \mathrm{mmHg})$, and $\mathrm{RPP}_{\text {submax }}(-17.6)$ displayed significant decreases.

With respect to the metabolic variables after $\mathrm{CR}, \mathrm{VO}_{2 \max }$ $(+2.7 \mathrm{~mL} / \mathrm{kg} / \mathrm{min}), \mathrm{V}_{\text {Emax }}(+8.0 \mathrm{~L} / \mathrm{min}), \mathrm{AT}(+0.17)$, and $\mathrm{O}_{\text {2pulsemax }}(+0.7)$ showed statistically significant increases (Table 2).

Change of $\mathrm{HR}_{\max }$ after $\mathrm{CR}$ according to reaching maximal limitation

Among the results of the ETT performed before CR, the 
Hyun Ho Kong, et al.

Table 1. Baseline patient characteristics

\begin{tabular}{|lccc}
\hline & $<\mathbf{5 5} \mathbf{~ y r}(\mathbf{n}=\mathbf{1 6})$ & $\mathbf{5 5} \mathbf{~ y r}(\mathbf{n}=\mathbf{1 6})$ & $\mathbf{p}$-value \\
\hline Age $(\mathrm{yr})$ & $47.0 \pm 5.5$ & $61.0 \pm 5.3$ & $<0.001$ \\
\hline BMI $\left(\mathrm{kg} / \mathrm{m}^{2}\right)$ & $26.7 \pm 3.3$ & $24.1 \pm 3.4$ & 0.10 \\
\hline Hypertension & 5 & 8 & 0.28 \\
\hline Diabetes mellitus & 2 & 2 & 1 \\
\hline Hyperlipidemia & 5 & 2 & 0.39 \\
\hline Current smoking & 11 & 10 & 0.71 \\
\hline Beta-blocker usage & 16 & 15 & 1 \\
\hline STEMI/NSTEMI & $11 / 5$ & $11 / 5$ & 1 \\
\hline No. of involved vessels & 1.7 & 1.9 & 0.45 \\
\hline EF (\%) & $58.9 \pm 9.2$ & $56.8 \pm 8.5$ & 0.61 \\
\hline Event to lst ETT (day) & 38.8 & 40.0 & 0.94 \\
\hline
\end{tabular}

Values are presented as mean \pm standard deviation or number.

BMI, body mass index; STEMI, ST segment elevation myocardial infarction; NSTEMI, non-ST segment elevation myocardial infarction; EF, ejection fraction; ETT, exercise tolerance test.

Table 2. Comparison of hemodynamic and metabolic variables after CR (all patients)

\begin{tabular}{lccc}
\hline \multicolumn{1}{c}{ Variable } & Baseline & After CR & Magnitude of change \\
\hline Duration $(\mathrm{s})$ & $792.6 \pm 104.7$ & $909.0 \pm 118.2^{* *}$ & 116.3 \\
$\mathrm{HR}_{\text {rest }}$ (beats/min) & $73.6 \pm 10.9$ & $68.3 \pm 10.0^{* *}$ & -5.3 \\
\hline $\mathrm{HR}_{\text {submax }}$ (beats/min) & $103.4 \pm 14.5$ & $97.6 \pm 11.1^{* *}$ & -5.8 \\
$\mathrm{HR}_{\text {max }}$ (beats/min) & $141.5 \pm 15.1$ & $148.8 \pm 16.4^{* *}$ & 7.3 \\
\hline $\mathrm{SBP}_{\text {rest }}(\mathrm{mmHg})$ & $113.2 \pm 11.5$ & $110.2 \pm 11.7^{*}$ & -2.9 \\
$\mathrm{SBP}_{\text {submax }}(\mathrm{mmHg})$ & $143.6 \pm 19.8$ & $134.5 \pm 17.3^{* *}$ & -9.1 \\
\hline $\mathrm{SBP}_{\text {max }}(\mathrm{mmHg})$ & $170.7 \pm 25.8$ & $172.7 \pm 21.2$ & 2.0 \\
$\mathrm{DBP}_{\text {rest }}(\mathrm{mmHg})$ & $68.3 \pm 10.5$ & $67.4 \pm 10.4$ & -0.9 \\
$\mathrm{DBP}_{\max }(\mathrm{mmHg})$ & $73.3 \pm 11.1$ & $72.5 \pm 12.1$ & -0.8 \\
$\mathrm{RPP}_{\text {submax }}$ & $149.3 \pm 35.1$ & $131.8 \pm 28.4^{* *}$ & -17.6 \\
$\mathrm{RPP}_{\text {max }}$ & $236.0 \pm 48.8$ & $249.5 \pm 46.0^{*}$ & 13.5 \\
$\mathrm{VO}_{2 \text { max }}(\mathrm{mL} / \mathrm{kg} / \mathrm{min})$ & $27.7 \pm 5.9$ & $30.5 \pm 6.2^{* *}$ & 2.7 \\
$\mathrm{~V}_{\text {Emax }}(\mathrm{L} / \mathrm{min})$ & $69.8 \pm 20.1$ & $77.8 \pm 21.1^{* *}$ & 8.0 \\
$\mathrm{AT}_{\mathrm{O}_{2 \text { pulsmax }}}^{1.27 \pm 0.32}$ & $1.44 \pm 0.37^{* *}$ & 0.17 \\
$\mathrm{RER}$ & $14.0 \pm 3.1$ & $14.7 \pm 3.4^{*}$ & 0.7 \\
\hline
\end{tabular}

Values are presented as mean \pm standard deviation.

CR, cardiac rehabilitation; HR, heart rate; SBP, systolic blood pressure; DBP, diastolic blood pressure; RPP, rate pressure product; $\mathrm{VO}_{2 \max }$, maximal oxygen consumption; $\mathrm{V}_{\mathrm{Emax}}$, maximal ventilation; $\mathrm{AT}$, anaerobic threshold; $\mathrm{O}_{2 \text { pulsemax }}$, maximal oxygen pulse; RER, respiratory exchange ratio.

${ }^{*} \mathrm{p}<0.05,{ }^{* *} \mathrm{p}<0.01$.

respiratory exchange ratio (RER), which is an indicator of whether a patient's exercise reached the patient's true maximal cardiopulmonary limitation [17], was used with a cut-off value of 1.0 to divide all patients into two groups. The magnitude of change in $\mathrm{HR}_{\max }$ before and after CR was +13.3 beats $/ \mathrm{min}$ in the $\mathrm{RER}<1.0$ group $(\mathrm{p}<0.05)$; whereas, the RER $\geq 1.0$ group displayed an increasing trend with +5.3 beats $/ \mathrm{min}$. However, the change was not statistically significant (Table 3). Moreover, when the patients were divided into two age groups with a cut-off age 
Table 3. Changes in $\mathrm{HR}_{\max }$ after CR according to deconditioned status

\begin{tabular}{lccccc}
\hline & \multicolumn{2}{c}{ Initial ETT RER $<\mathbf{1 . 0}(\mathbf{n}=\mathbf{6})$} & & \multicolumn{2}{c}{ Initial ETT RER $\geq \mathbf{1 . 0}(\mathbf{n}=\mathbf{2 6})$} \\
\cline { 2 - 3 } \cline { 5 - 6 } & \multicolumn{1}{c}{ Baseline } & After CR & & Baseline & After CR \\
\hline $\mathrm{HR}_{\max }$ (beats $\left./ \mathrm{min}\right)$ & $130.2 \pm 16.2$ & $146.2 \pm 16.9^{*}$ & & $144.2 \pm 13.9$ & $149.4 \pm 16.5$ \\
Age $(\mathrm{yr})$ & & $52.7 \pm 6.1$ & & \multicolumn{2}{c}{$54.3 \pm 9.4$} \\
\hline
\end{tabular}

Values are presented as mean \pm standard deviation.

$\mathrm{HR}_{\max }$, maximal heart rate; CR, cardiac rehabilitation; ETT, exercise tolerance test; RER, respiratory exchange ratio.

${ }^{*} \mathrm{p}<0.05$ for baseline and after CR in each group.

Table 4. Comparison of hemodynamic and metabolic variables after CR (by age group)

\begin{tabular}{|c|c|c|c|c|c|c|}
\hline \multirow{2}{*}{ Variable } & \multicolumn{3}{|c|}{$<55$ yr $(\mathrm{n}=16)$} & \multicolumn{3}{|c|}{$\geq 55$ yr $(n=16)$} \\
\hline & Baseline & After CR & \% change & Baseline & After CR & \% change \\
\hline Duration (s) & $833.3 \pm 85.5$ & $932.6 \pm 106.8^{* *}$ & $12.3 \pm 11.1$ & $752.0 \pm 108.7^{\mathrm{a})}$ & $885.3 \pm 127.6^{* *}$ & $18.7 \pm 16.0$ \\
\hline $\mathrm{HR}_{\text {rest }}$ (beats/min) & $75.0 \pm 12.3$ & $69.4 \pm 8.4^{* *}$ & $-6.7 \pm 7.5$ & $72.3 \pm 9.6$ & $67.2 \pm 11.6^{*}$ & $-6.8 \pm 11.2$ \\
\hline $\mathrm{HR}_{\text {submax }}$ (beats/min) & $101.0 \pm 8.4$ & $97.9 \pm 8.5$ & $-2.6 \pm 9.7$ & $105.9 \pm 18.7$ & $97.3 \pm 13.6^{* *}$ & $-7.2 \pm 9.4$ \\
\hline $\mathrm{HR}_{\max }$ (beats/min) & $146.5 \pm 11.3$ & $153.3 \pm 14.6$ & $5.0 \pm 10.8$ & $136.6 \pm 17.1$ & $144.3 \pm 17.2^{*}$ & $6.0 \pm 8.2$ \\
\hline $\mathrm{SBP}_{\text {rest }}(\mathrm{mmHg})$ & $112.1 \pm 11.5$ & $111.4 \pm 10.8$ & $-0.5 \pm 4.8$ & $114.2 \pm 11.9$ & $109.1 \pm 12.9 *$ & $-4.3 \pm 8.2$ \\
\hline $\mathrm{SBP}_{\text {submax }}(\mathrm{mmHg})$ & $138.0 \pm 18.4$ & $130.7 \pm 15.9$ & $-4.6 \pm 11.7$ & $149.1 \pm 20.2$ & $138.3 \pm 18.3^{*}$ & $-6.7 \pm 10.6$ \\
\hline $\mathrm{SBP}_{\max }(\mathrm{mmHg})$ & $172.4 \pm 30.5$ & $169.4 \pm 20.6$ & $-0.2 \pm 12.4$ & $168.9 \pm 21.0$ & $175.9 \pm 22.1^{*}$ & $4.4 \pm 9.4$ \\
\hline $\mathrm{DBP}_{\text {rest }}(\mathrm{mmHg})$ & $71.6 \pm 12.0$ & $69.4 \pm 10.6$ & $-1.8 \pm 14.7$ & $65.0 \pm 7.9^{a)}$ & $65.4 \pm 10.1$ & $1.4 \pm 16.0$ \\
\hline $\mathrm{DBP}_{\max }(\mathrm{mmHg})$ & $75.3 \pm 9.7$ & $77.4 \pm 13.1$ & $4.1 \pm 20.4$ & $71.2 \pm 12.3$ & $67.6 \pm 9.0$ & $-3.4 \pm 14.4$ \\
\hline $\mathrm{RPP}_{\text {submax }}$ & $139.2 \pm 20.3$ & $128.1 \pm 20.5^{*}$ & $-7.0 \pm 15.8$ & $159.5 \pm 43.7$ & $135.4 \pm 35.0^{* *}$ & $-13.0 \pm 16.2$ \\
\hline $\mathrm{RPP}_{\max }$ & $245.5 \pm 51.6$ & $250.8 \pm 39.6$ & $4.5 \pm 17.4$ & $226.4 \pm 45.4$ & $248.1 \pm 52.9^{*}$ & $10.4 \pm 15.0$ \\
\hline $\mathrm{VO}_{2 \max }(\mathrm{mL} / \mathrm{kg} / \mathrm{min})$ & $29.8 \pm 5.8$ & $32.0 \pm 6.9^{*}$ & $7.6 \pm 11.8$ & $25.7 \pm 5.3^{a)}$ & $29.0 \pm 5.2^{* *}$ & $13.6 \pm 10.1$ \\
\hline $\mathrm{V}_{\mathrm{Emax}}(\mathrm{L} / \mathrm{min})$ & $77.8 \pm 23.5$ & $84.2 \pm 22.1^{*}$ & $10.3 \pm 18.6$ & $61.8 \pm 12.1^{a)}$ & $71.4 \pm 18.5^{*}$ & $16.2 \pm 25.3$ \\
\hline AT & $1.39 \pm 0.33$ & $1.54 \pm 0.40^{*}$ & $11.4 \pm 14.6$ & $1.14 \pm 0.26$ & $1.34 \pm 0.32^{* *}$ & $19.6 \pm 27.3$ \\
\hline $\mathrm{O}_{2 \text { pulsemax }}$ & $15.4 \pm 2.8$ & $15.9 \pm 3.7$ & $2.9 \pm 12.1$ & $12.6 \pm 2.9^{\mathrm{a})}$ & $13.5 \pm 2.7^{*}$ & $8.5 \pm 12.1$ \\
\hline RER & $1.11 \pm 0.10$ & $1.17 \pm 0.11$ & $5.2 \pm 10.4$ & $1.08 \pm 0.14$ & $1.12 \pm 0.14$ & $5.4 \pm 17.8$ \\
\hline
\end{tabular}

Values are presented as mean \pm standard deviation.

CR, cardiac rehabilitation; HR, heart rate; SBP, systolic blood pressure; DBP, diastolic blood pressure; RPP, rate pressure product; $\mathrm{VO}_{2 \max }$, maximal oxygen consumption; $\mathrm{V}_{\mathrm{Emax}}$, maximal ventilation; $\mathrm{AT}$, anaerobic threshold; $\mathrm{O}_{2 \text { pulsemax }}$, maximal oxygen pulse; RER, respiratory exchange ratio.

${ }^{*} \mathrm{p}<0.05$ for baseline and after CR in each group.

${ }^{* *} \mathrm{p}<0.01$ for baseline and after CR in each group.

a) $<0.05$ for comparing the young and the old at baseline.

of 55 years, both groups exhibited a mean RER value of 1.0 or greater in the ETT performed before CR. The percentage of patients with a RER of 1.0 or greater did not differ between the two groups with an $81 \%$ represented in both the young and old groups ( $\mathrm{n}=13 \mathrm{each})$. Even in the test after $\mathrm{CR}$, the two groups exhibited no difference in this regard, at $94 \%$ in each group ( $\mathrm{n}=15$ each) (Table 4$)$.
Hemodynamic and metabolic changes after CR by age group

Before CR, the older group had a significantly shorter exercise duration (-81 s) and significantly lower $\mathrm{VO}_{2 \max }$ $(-4.1 \mathrm{~mL} / \mathrm{kg} / \mathrm{min}), \mathrm{V}_{\text {Emax }}(-16 \mathrm{~L} / \mathrm{min})$, and $\mathrm{O}_{2 \text { pulsemax }}(-2.8)$ than the young group. These results indicate a decreasing trend in overall exercise capacity with increases in age.

After the 8-week CR therapy in the older group, significant improvements were seen in all variables except for diastolic blood pressure (DBP); that is, significant increases 
were observed in exercise duration $(+133.3 \mathrm{~s}), \mathrm{HR}_{\max }(+7.7$ beats/min), $\mathrm{SBP}_{\max }(+7.0 \mathrm{mmHg})$, and $\mathrm{RPP}_{\max }(+21.7)$ and significant decreases were observed in $\mathrm{HR}_{\text {rest }}(-5.1$ beats/ $\mathrm{min}), \mathrm{SBP}_{\text {rest }}(-5.1 \mathrm{mmHg}), \mathrm{HR}_{\text {submax }}(-8.6$ beats $/ \mathrm{min}), \mathrm{SB}-$ $\mathrm{P}_{\text {submax }}(-10.8 \mathrm{mmHg})$, and $\mathrm{RPP}_{\text {submax }}(-24.1)$. However, in the young group, among the hemodynamic variables, a significant increase in exercise duration (+99.4 s) and significant decreases in $\mathrm{HR}_{\text {rest }}(-5.6$ beats $/ \mathrm{min})$ and $\mathrm{RPP}_{\text {submax }}$ $(-11.1)$ were evidenced. All other variables were not statistically significant.

With respect to metabolic variables, after $\mathrm{CR}$, both groups demonstrated significant increases in $\mathrm{VO}_{2 \max }, \mathrm{V}_{\mathrm{Emax}}$, and AT. However, only the older group had a significant increase in the $\mathrm{O}_{\text {2pulsemax }}$, from $12.6 \pm 2.9$ before exercise to 13.5 \pm 2.7 after exercise (Table 4 ).

\section{Comparison of hemodynamic and metabolic changes after CR between the young and the old groups}

There were no statistically significant differences in the percent change of all hemodynamic variables from before to after CR in the two age groups. However, compared to the young group, the older group exhibited a higher percent change in $\mathrm{HR}_{\text {submax }}(-2.6 \%$ vs. $-7.2 \%), \mathrm{RPP}_{\text {submax }}$ $(-7.0 \%$ vs. $-13.0 \%)$, and $\mathrm{RPP}_{\max }(4.5 \%$ vs. $10.4 \%)$. Furthermore, there were no significant differences in the percent change of all metabolic variables after CR in the two age groups. However, the older group experienced a higher percent change in $\mathrm{VO}_{2 \max }(7.6 \%$ vs. $13.6 \%)$, AT $(11.4 \%$ vs. $19.6 \%)$, and $\mathrm{O}_{2 \text { pulsemax }}(2.9 \%$ vs. $8.5 \%$ ) (Table 4$)$.

\section{Cardiovascular complications during exercise}

During the ETT and CR exercises, there were no abnormal ECG findings, such as sustained ventricular tachycardia. Furthermore, there were no major cardiac complications, such as abnormal hemodynamic response, MI, cardiac arrest, and syncope in both groups.

\section{DISCUSSION}

Improvement in exercise capacity with CR can be attributed to improved heart function, such as increases in stroke volume [18] and coronary perfusion due to improved endothelium-dependent coronary vasodilation [19], as well as increased peripheral oxygen extraction (such as increases in capillaries in peripheral skeletal muscles, myoglobin count, number and size of mito- chondria and oxidase level) [3].

Administered CR to patients with coronary artery disease results in hemodynamic changes including decreased HR, BP, and RPP at rest and under the same exercise intensity, because of the physiological changes already mentioned. These changes in turn increased the exercise tolerance of daily living activities [20]. CR is also known to increase $\mathrm{RPP}_{\max }$ upon angina onset through increased coronary perfusion $[1,21]$. In addition, metabolically, the $\mathrm{VO}_{2 \max }$ increases, which is an important variable related to the patient's prognosis [3]. The $\mathrm{V}_{\mathrm{Emax}}$ increases, which indicates effective oxygen delivery to the tissues, carbon dioxide emission, and lactic acid neutralization [22]. In addition, AT, as a key predictor of endurance, increases because of the ability to perform higher intensity exercise without lactic acid accumulation [3]. Furthermore, the oxygen consumption per pulse at peak exercise intensity, expressed as $\mathrm{O}_{2 \text { pulsemax }}$, reflects cardiovascular efficiency during exercise and is an important factor in predicting the prognosis of CAD patients similar to $\mathrm{VO}_{2 \max }$. $\mathrm{O}_{\text {2pulsemax }}$ also increases with CR [23].

The findings of the current study with regard to changes in hemodynamic and metabolic variables after CR in the entire patient population are in line with previous studies (Table 2), except for the $\mathrm{HR}_{\text {max }}$. The $\mathrm{HR}_{\max }$ is determined by age, and therefore should display no change or decrease after aerobic exercise [24]. However, in the current study, it demonstrated an increasing pattern. When an initial ETT was performed in a deconditioning state for various reasons such as the medical condition before $C R$, the initial $\mathrm{HR}_{\max }$ was measured lower than expected due to the failure of the patient reaching the maximal cardiopulmonary limitation. As such, the changes in $\mathrm{HR}_{\max }$ may appear to have increased due to aerobic exercise since it improves in a deconditioning state after CR. In our study, only the RER $>1.0$ group exhibited a significant increase in the $\mathrm{HR}_{\max }$; which indicates that the results were affected by patients who failed to reach their true maximal limitation due to deconditioning prior to CR (Table 3).

However, conflicting results were found in the analysis with the patients divided into two groups based on age. Among the hemodynamic variables, the young group exhibited significant changes only in exercise duration, $\mathrm{HR}_{\text {rest }}$, and $\mathrm{RPP}_{\text {submax }}$; whereas, the older group showed significant changes in all hemodynamic variables except for DBP (Table 4). In particular, although the magnitude 
of change in $\mathrm{RPP}_{\text {submax }}$ was not significant, it tended to be higher in the older group, which indicates that the elderly have a greater potential for performing higher intensity activities with the same RPP after CR. In addition, considering that there were no differences in the rate of reaching the true maximal cardiopulmonary limitation in the ETT between the two age groups, we speculate that the higher percent change of $\mathrm{RPP}_{\max }$ in the older group could be attributed to increased myocardial oxygen delivery because of exercise training [19]. This outcome was also confirmed in a study by DeSouza et al. [25] that demonstrated that the endothelium-dependent vasodilation effect from exercise training was more pronounced among the elderly.

With respect to metabolic changes based on age, the young group showed a pattern of increasing $\mathrm{O}_{2 \text { pulsemax }}$, but this change was not statistically significant. Whereas, the older group experienced significant increases in all metabolic variables, including the $\mathrm{O}_{\text {2pulsemax }}$ (Table 4). Although there were no statistically significant differences in the magnitude of change between the young and old groups, the older group displayed a greater margin of change. As in the case of the hemodynamic variables, this outcome indicates that although the older group showed lower metabolic variables, the effects of CR were equivalent to or higher compared with those in the young group.

In healthy adults, an increase in age is associated with a lower ejection fraction, $\mathrm{HR}_{\max }$, and arteriovenous oxygen difference, as well as reduced blood flow to and capillary density of skeletal muscles during peak exercise intensity, which results in a gradual decrease in exercise capacity [26]. However, several studies have shown that despite these physiological disadvantages, the elderly exhibited comparable or even greater improvement in exercise capacity than the younger populations $[6,7]$, which aligns with the results of this study. In a previous study, compared to the young, CR was perceived less effective in the elderly because the elderly tended to have diminished exercise capacity and accompanying diseases that can interfere with exercise [5]. However, the findings of this study confirm that CR can generate greater hemodynamic and metabolic changes in the elderly than in the younger populations. Therefore, it is necessary to actively encourage older patients to participate in CR.

The present study had some limitations. First, the sample size was small, and because all of the patients were males, the findings may not be generalizable. Therefore, future studies that include a greater number of patients for analysis by age and sex are necessary. Second, only the short-term effects of CR were assessed, and only the results immediately before and after CR were compared. Therefore, studies with a long-term follow-up are necessary to assess the long-term effects of CR. Finally, this study included only patients who underwent PCI after AMI. Therefore, these findings may not be applicable to patients who underwent other procedures, such as coronary artery bypass surgery, or to patients with other heart diseases, such as chronic heart failure and heart valve disease.

In conclusion, those who were 55 years and older had significantly better hemodynamic and metabolic improvements after CR for AMI than the younger populations. Therefore, the CR program must be actively recommended to older patients with MI.

\section{CONFLICT OF INTEREST}

No potential conflict of interest relevant to this article was reported.

\section{REFERENCES}

1. Thompson PD, Buchner D, Pina IL, Balady GJ, Williams MA, Marcus BH, et al. Exercise and physical activity in the prevention and treatment of atherosclerotic cardiovascular disease: a statement from the Council on Clinical Cardiology (Subcommittee on Exercise, Rehabilitation, and Prevention) and the Council on Nutrition, Physical Activity, and Metabolism (Subcommittee on Physical Activity). Circulation 2003;107:3109-16.

2. May GA, Nagle FJ. Changes in rate-pressure product with physical training of individuals with coronary artery disease. Phys Ther 1984;64:1361-6.

3. Jones AM, Carter H. The effect of endurance training on parameters of aerobic fitness. Sports Med 2000;29: 373-86.

4. Cortes O, Arthur HM. Determinants of referral to cardiac rehabilitation programs in patients with coronary artery disease: a systematic review. Am Heart J 2006; 151:249-56.

5. Brown TM, Hernandez AF, Bittner V, Cannon CP, Ell- 
rodt G, Liang L, et al. Predictors of cardiac rehabilitation referral in coronary artery disease patients: findings from the American Heart Association's Get With The Guidelines Program. J Am Coll Cardiol 2009;54: 515-21.

6. Balady GJ, Jette D, Scheer J, Downing J. Changes in exercise capacity following cardiac rehabilitation in patients stratified according to age and gender. Results of the Massachusetts Association of Cardiovascular and Pulmonary Rehabilitation Multicenter Database. J Cardiopulm Rehabil 1996;16:38-46.

7. Marchionni N, Fattirolli F, Fumagalli S, Oldridge N, Del Lungo F, Morosi L, et al. Improved exercise tolerance and quality of life with cardiac rehabilitation of older patients after myocardial infarction: results of a randomized, controlled trial. Circulation 2003;107: 2201-6.

8. Beere PA, Russell SD, Morey MC, Kitzman DW, Higginbotham MB. Aerobic exercise training can reverse age-related peripheral circulatory changes in healthy older men. Circulation 1999;100:1085-94.

9. Stratton JR, Levy WC, Cerqueira MD, Schwartz RS, Abrass IB. Cardiovascular responses to exercise. Effects of aging and exercise training in healthy men. Circulation 1994;89:1648-55.

10. Ades PA, Grunvald MH. Cardiopulmonary exercise testing before and after conditioning in older coronary patients. Am Heart J 1990;120:585-9.

11. Fletcher GF, Ades PA, Kligfield P, Arena R, Balady GJ, Bittner VA, et al. Exercise standards for testing and training: a scientific statement from the American Heart Association. Circulation 2013;128:873-934.

12. Kovacs G, Olschewski A, Berghold A, Olschewski H. Pulmonary vascular resistances during exercise in normal subjects: a systematic review. Eur Respir J 2012;39:319-28.

13. van Empel VP, Kaye DM, Borlaug BA. Effects of healthy aging on the cardiopulmonary hemodynamic response to exercise. Am J Cardiol 2014;114:131-5.

14. Karvonen MJ, Kentala E, Mustala O. The effects of training on heart rate; a longitudinal study. Ann Med Exp Biol Fenn 1957;35:307-15.

15. American Association of Cardiovascular and Pulmonary Rehabilitation. Guidelines for cardiac rehabilitation and secondary prevention programs. 5th ed. Champaign: Human Kinetics; 2013. p. 80-1.
16. Ades PA, Savage PD, Brawner CA, Lyon CE, Ehrman JK, Bunn JY, et al. Aerobic capacity in patients entering cardiac rehabilitation. Circulation 2006;113:270612.

17. Guazzi M, Arena R, Halle M, Piepoli MF, Myers J, Lavie CJ. 2016 Focused update: clinical recommendations for cardiopulmonary exercise testing data assessment in specific patient populations. Circulation 2016;133: e694-711.

18. Hambrecht R, Gielen S, Linke A, Fiehn E, Yu J, Walther $\mathrm{C}$, et al. Effects of exercise training on left ventricular function and peripheral resistance in patients with chronic heart failure: a randomized trial. JAMA 2000; 283:3095-101.

19. Hambrecht R, Wolf A, Gielen S, Linke A, Hofer J, Erbs S, et al. Effect of exercise on coronary endothelial function in patients with coronary artery disease. $\mathrm{N}$ Engl J Med 2000;342:454-60.

20. Clausen JP, Trap-Jensen J. Heart rate and arterial blood pressure during exercise in patients with angina pectoris. Effects of training and of nitroglycerin. Circulation 1976;53:436-42.

21. Sim DN, Neill WA. Investigation of the physiological basis for increased exercise threshold for angina pectoris after physical conditioning. J Clin Invest 1974;54: 763-70.

22. Wasserman K, Whipp BJ, Koyl SN, Beaver WL. Anaerobic threshold and respiratory gas exchange during exercise. J Appl Physiol 1973;35:236-43.

23. Oliveira RB, Myers J, Araujo CG, Abella J, Mandic S, Froelicher V. Maximal exercise oxygen pulse as a predictor of mortality among male veterans referred for exercise testing. Eur J Cardiovasc Prev Rehabil 2009; 16:358-64.

24. Whyte GP, George K, Shave R, Middleton N, Nevill AM. Training induced changes in maximum heart rate. Int J Sports Med 2008;29:129-33.

25. DeSouza CA, Shapiro LF, Clevenger CM, Dinenno FA, Monahan KD, Tanaka H, et al. Regular aerobic exercise prevents and restores age-related declines in endothelium-dependent vasodilation in healthy men. Circulation 2000;102:1351-7.

26. Ogawa T, Spina RJ, Martin WH 3rd, Kohrt WM, Schechtman KB, Holloszy JO, et al. Effects of aging, sex, and physical training on cardiovascular responses to exercise. Circulation 1992;86:494-503. 